\title{
Numerical Simulation of Heat Transfer from Rotary Cylinder by Spray Cooling
}

\author{
Yong Qi LIU*, Sen LU, Bin ZHENG, Peng SUN \\ School of Transportation and Vehicle Engineering, Shandong University of Technology, Zibo, 255000, China \\ crossref http://dx.doi.org/10. 5755/j01.ms.23.4.17322
}

Received 23 December 2016; accepted 07 April 2017

\begin{abstract}
A commonly-used method to cool rotating cylinders involves spraying water on the surface to cool its internal particles. This paper conducted a numerical investigation of heat transfer from a rotary cylinder cooled with sprayed water. A 3-D numerical model was generated, and the distributions of the wall temperatures and liquid films were analyzed. Then, the heat transfer characteristics for different parameters were obtained and compared. The results showed that the best location for a single spray nozzle was directly above the cylinder, where it had the most uniform liquid film and highest heat exchange efficiency. With increased rotation speeds, the cylinder wall temperature increased and the distribution of wall temperature and liquid film became more uniform, which improved heat transfer. Because of the influence of gravity, the slope of the cylinder had a negative influence on the distribution of the liquid film. When the cylinder material had lower thermal conductivity, the system needed a much longer period of time before it was stable and had lower heat flux. Furthermore, with the same heat source, the system heat flux could not be determined with only the outer surface temperature, but with the temperature difference between inner surface and outer surface.

Keywords: rotary cylinder, spray cooling, body material, tilt angle.
\end{abstract}

\section{INTRODUCTION}

Rotary coolers are a common industrial device used for material transport and cooling. The usual cooling methods involve air cooling on the inside and water cooling on the outside. The latter requires large amounts of coolant, and the heat efficiency is not optimal. Air cooling requires hot material to come into contact with air, which is forbidden in industries such as food and smelting. As a new cooling technology, spray cooling has many advantages including high effectiveness, even cooling, and efficient use of coolant. Research results have shown maximum heat flux surpassing $1200 \mathrm{~W} / \mathrm{cm}^{2}$ in laboratory tests [1].

However, research on spray cooling has primarily focused on flat and micro-structured surfaces; studies on rotary cylinders are uncommon [2-7]. Yoon investigated the droplet behaviors of spray impacting a stationary cylinder and found that cylinder temperature had great influence on droplet distribution and velocity [8]. Elghnam studied heat transfer characteristics of a rotating cylinder in ambient air [9]. The effects of rotation were presented in terms of local and average Nusselt numbers. Jafari researched the process of cooling hot tomato juice cans, and the simulation results were in agreement with experimental results [10]. Lu conducted experimental research on cooling rotary cylinders and temperature distributions of their outer surfaces under different rotational speeds [11].

In this paper, a simulation study was conducted on spray-cooling rotary cylinders. Experimental studies have determined that when spraying, the temperature of the cooling surface is usually lower than the boiling point of water because of the thermal contact resistant between the heater and the cylinder [11]. As such, this research focused only on single-phase heat transfer.

\footnotetext{
* Corresponding author. Tel.: +86-0533-2781015

E-mail address: Liuyq65@163.com (Y.Q. Liu)
}

\begin{tabular}{|c|c|}
\hline \multicolumn{2}{|c|}{ Nomenclature } \\
\hline$q$ & Heat flux, $\mathrm{W} / \mathrm{m}^{2}$ \\
\hline$\chi$ & Thermal conductivity, $\mathrm{W} / \mathrm{mK}$ \\
\hline$T$ & Temperature, $\mathrm{K}$ \\
\hline$\rho$ & Density, $\mathrm{kg} / \mathrm{m}^{3}$ \\
\hline$u_{i}$ & Velocity components, $\mathrm{m} / \mathrm{s}$ \\
\hline$S_{m}$ & Source term of mass, $\mathrm{kg} / \mathrm{m}^{3} \mathrm{~s}$ \\
\hline$S_{m o}$ & Source term of momentum, $\mathrm{kg} / \mathrm{m}^{2} \mathrm{~s}^{2}$ \\
\hline$S_{e}$ & Source term of energy, $\mathrm{W} / \mathrm{m}^{3}$ \\
\hline$P$ & Pressure, $\mathrm{Pa}$ \\
\hline$\mu$ & Dynamic viscosity of water, $\mathrm{kg} / \mathrm{ms}$ \\
\hline$\delta_{i j}$ & Mean strain tensor, $1 / \mathrm{s}$ \\
\hline$f_{i}$ & Volume force components, $\mathrm{m} / \mathrm{s}^{2}$ \\
\hline$h$ & Internal energy, $\mathrm{J} / \mathrm{kg}$ \\
\hline$\tau_{i j}$ & Shear stress, $\mathrm{N} / \mathrm{m}^{2}$ \\
\hline$i, j$ & Cartesian coordinate directions \\
\hline
\end{tabular}

\section{GOVERNING EQUATIONS}

The energy transfer process used in this study is demonstrated in Fig. 1. First, the heat reached the cylinder wall by conduction and radiation. Then, the liquid film formed by spraying carried the heat away by convection. During this simulation, radiation was disregarded.

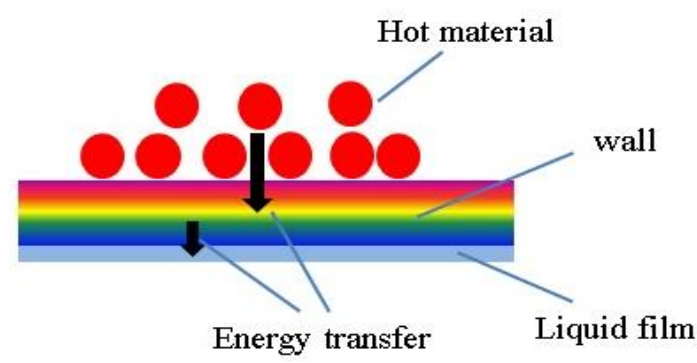

Fig. 1. Heat transfer process 
In the first part of the simulation, the heat transfer equation was as follows:

$q=-\lambda \frac{\mathrm{d} T}{\mathrm{~d} x_{i}}$

The equation for the second part of the simulation was as follows:

$\frac{\partial \rho u_{i}}{\partial x_{i}}=S_{m}$

$\frac{\partial\left(\rho u_{i} u_{j}\right)}{\partial x_{j}}=-\frac{\partial p}{\partial x_{j}}+\frac{\partial}{\partial x_{j}}\left(-\frac{2}{3} \mu \frac{\partial u_{i}}{\partial x_{i}} \delta_{i j}+\mu\left(\frac{\partial u_{i}}{\partial x_{j}}+\frac{\partial u_{j}}{\partial x_{i}}\right)\right)+\rho f_{i}+S_{m o}$

$\rho \frac{\partial}{\partial x_{j}}\left(h+\frac{u_{i} u_{i}}{2}\right)=\rho f_{i} u_{i}+\frac{\partial\left(\tau_{i j} u_{j}\right)}{\partial x_{i}}+\frac{\partial}{\partial x_{i}}\left(\lambda \frac{\partial T}{\partial x_{i}}\right)+S_{e}$.

Parameters $S_{\mathrm{m}}, S_{\mathrm{mo}}, S_{\mathrm{e}}$ denoted the source terms of droplet mass, momentum, and energy, respectively.

\section{COMPUTATIONAL GEOMETRY}

Fig. 2 shows the details of the cylinder 3-D model. The material of cylinder was aluminum (AL, 202.4 W/mK). The coolant temperature was $298 \mathrm{~K}$. Set tilt angle $2^{\circ}$ and rotating speed $6 \mathrm{r} / \mathrm{min}$ as default. The hot material was simplified to a heat source at the bottom of the cylinder; its temperature was remained $373.15 \mathrm{~K}$. The heat source did not roll with cylinder. And the thermal contact resistant was neglected too.
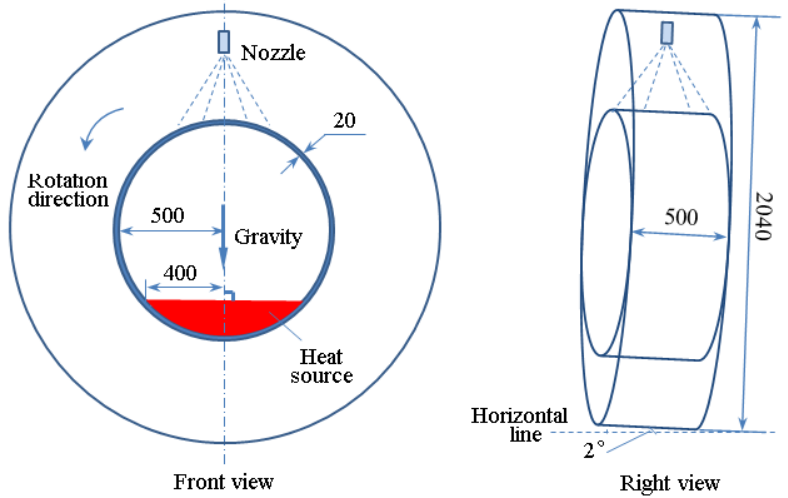

Fig. 2. Geometry of rotary cylinder

According to Mudawar's research, maximum heat flux is obtained when the spray impact area inscribes the heated surface [12]. The nozzle in this research was kept motionless and stayed directly above the surface. The specific information of the spray is summarized in Table 1. The simulation was conducted with CFD software Fluent. Rosin-Rammler distribution was chosen for the spray droplet size, SST $k-w$ was chosen for the turbulence model, and discrete particle model was chosen for the forming of the spray. The grid was made of hexahedral elements and optimized with a fine mesh near the boundaries. The resulting grid and boundary conditions are shown in Fig. 3.

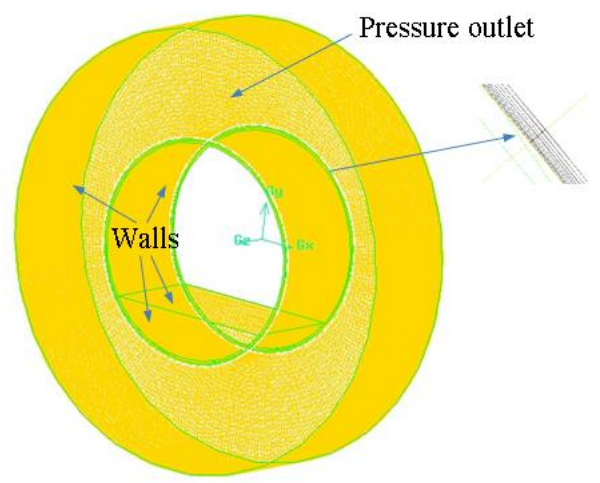

Fig. 3. Grid structure of the computational model

\section{RESULTS AND DISCUSSION}

\subsection{Stabilizing time}

The average temperatures of the outer surface are shown in Fig. 4. The time needed for the system to become stable was about the same for all nozzle locations, rotation speeds, and tilt angles (see Fig. 4 a). After 60 seconds, the temperature increased slowly - less than $1 \mathrm{~K}$ per $10 \mathrm{~s}-$ which was recognized as stable. However, when the cylinder material was changed from aluminum to steel, the time needed to stabilize the system increased dramatically to 200 seconds, an increase of more than three times. Fig. 5 shows the wall temperature distributions when the system was stable under default conditions.

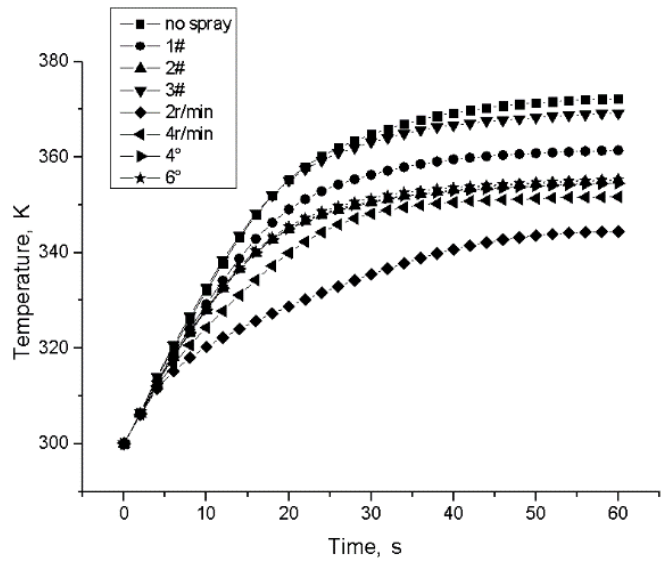

a

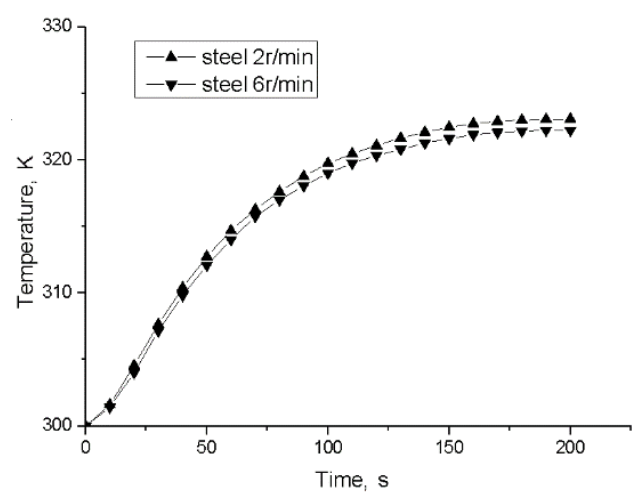

b

Fig. 4. Outer surface temperature variation as function of time for different conditions: a-aluminum cylinder; $b$-steel cylinder 
Table 1. Operating parameters

\begin{tabular}{|c|c|c|c|c|c|c|c|}
\hline $\begin{array}{c}\text { Coolant } \\
\text { temperature, } \mathrm{K}\end{array}$ & $\begin{array}{c}\text { Cone } \\
\text { angle, }^{\circ}\end{array}$ & $\begin{array}{c}\text { Material } \\
\text { temperature, } \mathrm{K}\end{array}$ & $\begin{array}{c}\text { Flow rate, } \\
\mathrm{kg} / \mathrm{s}\end{array}$ & $\begin{array}{c}\text { Orifice } \\
\text { diameter, } \mathrm{mm}\end{array}$ & $\begin{array}{c}\text { Droplet } \\
\text { velocity, } \mathrm{m} / \mathrm{s}\end{array}$ & $\begin{array}{c}\text { SMD, } \\
\mathrm{mm}\end{array}$ & $\begin{array}{c}\text { Nozzle-to-surface } \\
\text { spacing, } \mathrm{mm}\end{array}$ \\
\hline 298.15 & 27.51 & 373.15 & 0.5 & 7 & 10 & 0.3 & 480 \\
\hline
\end{tabular}

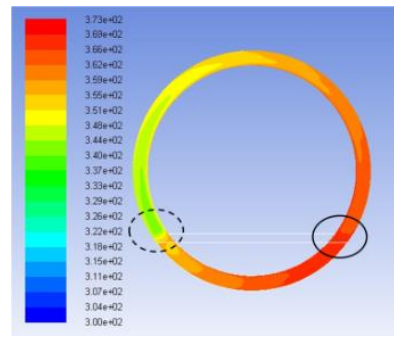

a

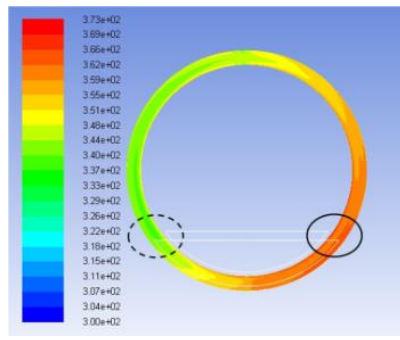

b

Fig. 5. Distribution of wall temperature: $a$-inner surface; $b$ - outer surface

\subsection{Nozzle location}

For single-nozzle spray cooling, the location of the nozzle is very important. Three locations were studied and compared, as shown in Fig. 6. To represent the surface temperatures, there were eight positions from which the temperatures were collected when the system was stable.

$3 \#$

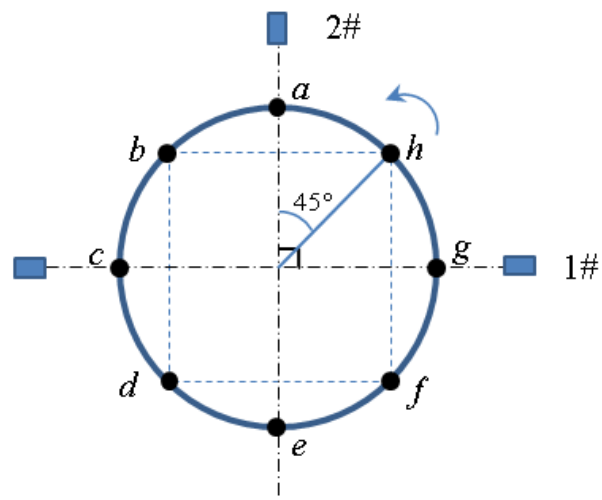

Fig. 6. Three spraying locations and eight temperature collecting positions

The temperature distributions are shown in Fig. 7.

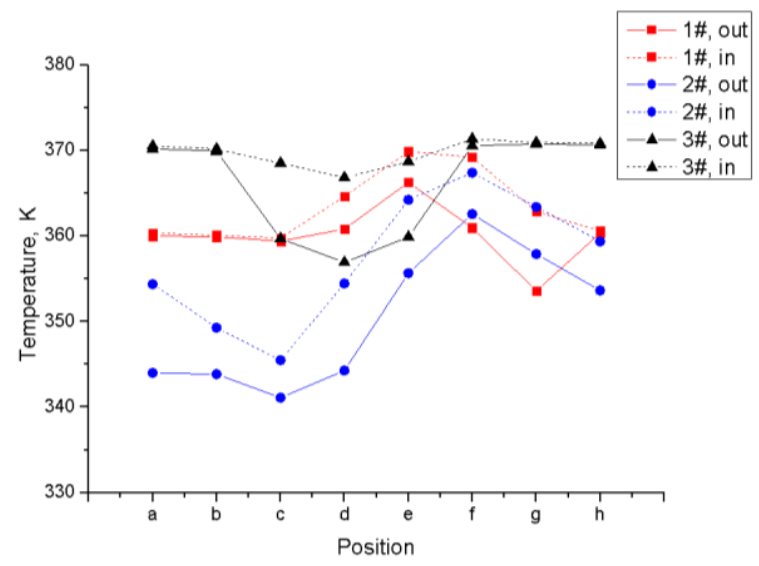

Fig. 7. Temperature distribution with different spraying locations

For \#1, the lowest temperature position (LTO) of the outer surface was located at the spraying area, where the temperature first increased and then decreased. This was due to strong wall heat conduction. Different from \#1, the LTO for \#3 was under the spraying area, which meant the convection was stronger than the conduction. The distributions of the liquid film are shown in Fig. 8. The thickness is presented by $\mathrm{mm}$. It was clear that \#2 had the most uniform film, with \#1 and \#3 showing much less uniform coverage. Because of the tilt angle and influence of gravity, there was an ultrathin film area on the outer surface of spray position $\# 2$.

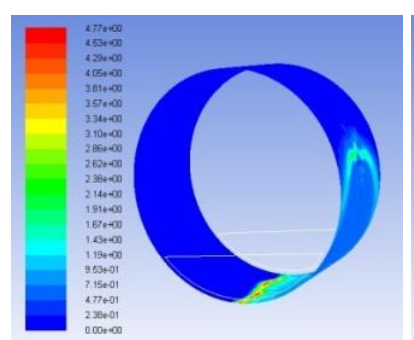

a

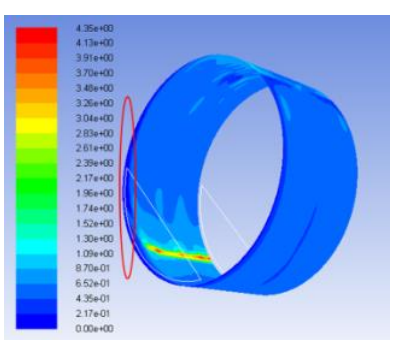

b

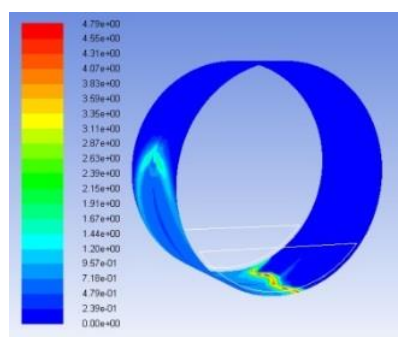

Fig. 8. Distribution of liquid film under different spray position: $a-1 \# ; b-2 \# ; c-3 \#$

The temperatures and system heat fluxes under different locations are shown in Table 2. Number 2 showed the lowest temperature on both surfaces and the highest heat transfer efficiency, which was more than twice those of \#1 and \#3. Furthermore, \#1 was $25 \%$ more than \#3.

Table 2. Properties under different spray position

\begin{tabular}{|c|c|c|c|}
\hline \multirow{2}{*}{$1 \#$} & Inner surface, $\mathrm{K}$ & Outer surface, $\mathrm{K}$ & Heat flux, $\mathrm{J} / \mathrm{m}^{2} \cdot \mathrm{s}$ \\
\cline { 2 - 4 } & 363.196 & 360.953 & 97331.1 \\
\hline $2 \#$ & 356.985 & 351.469 & 208349.1 \\
\hline $3 \#$ & 370.044 & 368.042 & 78118.5 \\
\hline
\end{tabular}

\subsection{Rotation speed}

With the nozzle location maintained at position $\# 2$, the cylinder rotation speed was changed from $6 \mathrm{r} / \mathrm{min}$ to $4 \mathrm{r} / \mathrm{min}$ and $2 \mathrm{r} / \mathrm{min}$. Fig. 9 shows the resultant temperature distributions. It was discovered that the slower the speed, the larger the low temperature region became; the temperature difference became larger as well.

Table 3 shows the temperature and heat flux measurements at different rotational speeds. When the rotation speed was increased, the inner and outer surface temperatures and material heat flux also increased that agreed with the experimental results [11]. But the growth 
rate of flux is much larger than that of experiments by the influence of different body materials.

It was different from location case which higher heat flux happened on lower temperature outer surface, but it could also be found that with the temperature difference between inner and outer surface became bigger the heat flux increased which could be found in all cases.

There was little difference between the distributions of the liquid films under different rotation speeds. Fig. $8 \mathrm{~b}$ can be used as reference.

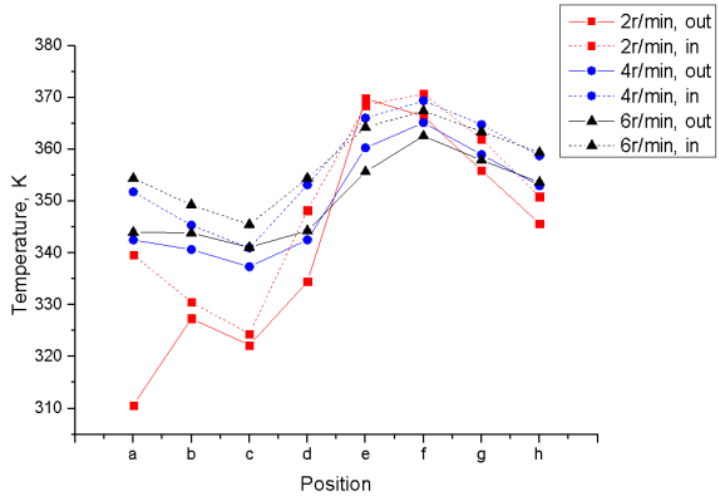

Fig. 9. Temperature distribution with different rotation speeds

Table 3. Properties under different rotation speed

\begin{tabular}{|c|c|c|c|}
\hline \multirow{2}{*}{$2 \mathrm{r} / \mathrm{min}$} & Inner surface, $\mathrm{K}$ & Outer surface, $\mathrm{K}$ & Heat flux, $\mathrm{J} / \mathrm{m}^{2} \mathrm{~s}$ \\
\cline { 2 - 4 } & 348.832 & 344.063 & 171690.8 \\
\hline $4 \mathrm{r} / \mathrm{min}$ & 356.017 & 350.854 & 185067.1 \\
\hline $6 \mathrm{r} / \mathrm{min}$ & 356.985 & 351.469 & 208349.1 \\
\hline
\end{tabular}

\subsection{Tilt angle}

The tilt angles were changed from $2^{\circ}$ to $4^{\circ}$ and $6^{\circ}$. As shown in Fig. 10, there was little change in the temperatures between the different angles.

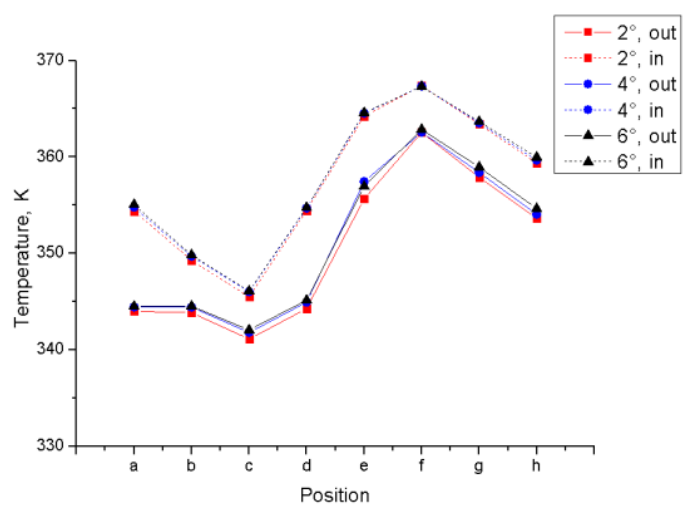

Fig. 10. Temperature distribution with different tilt angles

However, the liquid film, which can be seen in Fig. 11, was greatly affected; the ultrathin coverage area became larger when the angle was greater. Table 4 shows that the larger angles caused higher temperatures and lower heat fluxes, although the differences were small.

Table 4. Properties under different tilt angle

\begin{tabular}{|c|c|c|c|}
\hline & Inner surface, $\mathrm{K}$ & Outer surface, $\mathrm{K}$ & Heat flux, $\mathrm{J} / \mathrm{m}^{2} \cdot \mathrm{s}$ \\
\cline { 2 - 4 } $2^{\circ}$ & 356.985 & 351.469 & 208349.1 \\
\hline $4^{\circ}$ & 357.309 & 351.913 & 207387.5 \\
\hline $6^{\circ}$ & 357.460 & 352.167 & 207158.3 \\
\hline
\end{tabular}

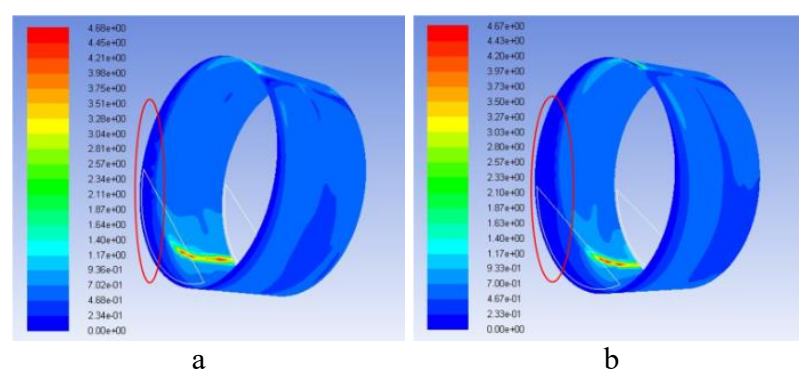

Fig. 11. Distribution of liquid film under different tilt angle: $a-4^{\circ}$ tilt angle; $b-6^{\circ}$ tilt angle

\subsection{Body material}

The cylinder material was changed from aluminum to steel (ST, 16.27 W/mK). As Fig. 12 shows, a comparison of the aluminum cylinder versus the steel cylinder was conducted at two different rotation speeds. Overall, the changes between the different rotation speeds were lower with the steel compared to the aluminum, and there was a decrease in the outer surface temperature

As shown in Table 5, heat flux revealed that heat transfer increased when the cylinder's thermal conductivity decreased. With the cylinder made of steel, the rotation speed had a small influence on heat transfer which was in accordance with experiment conclusion [11], and the system heat flux increased at the higher rotation speed.

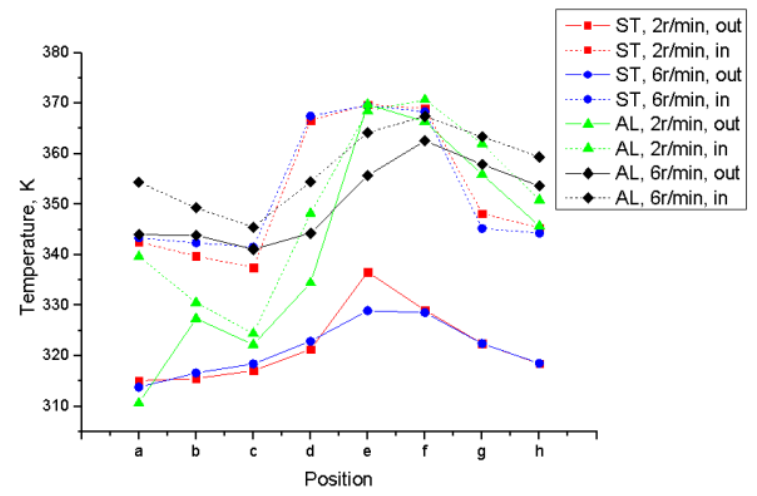

Fig. 12. Temperature distributions with different materials

Table 5. Properties under different materials and rotation speeds

\begin{tabular}{|c|c|c|c|}
\hline & Inner surface, $\mathrm{K}$ & Outer surface, $\mathrm{K}$ & Heat flux, $\mathrm{J} / \mathrm{m}^{2} \cdot \mathrm{s}$ \\
\cline { 2 - 4 } $2 \mathrm{r} / \mathrm{min} \mathrm{St}$ & 350.768 & 323.078 & 81054.8 \\
\hline $2 \mathrm{r} / \mathrm{min} \mathrm{Al}$ & 348.832 & 344.063 & 171690.8 \\
\hline $6 \mathrm{r} / \mathrm{min} \mathrm{St}$ & 351.149 & 322.228 & 82520.0 \\
\hline $6 \mathrm{r} / \mathrm{min} \mathrm{Al}$ & 356.985 & 351.469 & 208349.1 \\
\hline
\end{tabular}

\section{CONCLUSIONS}

In this work, a numerical study was carried out involving rotating cylinders cooled by water spray. A few system parameters' influences were studied. The results showed good agreement with experimental results. The simulation results determined the following to be true:

1. For single-nozzle spray cooling, the optimum location of the nozzle was directly above the barrel, where it created the most uniform liquid film and the heat flux was double that of the right or left spray position;

2. Raising the cylinder's rotation speed improved heat 
transfer efficiency. The cylinder wall demonstrated a more uniform temperature distribution when the rotation speed increased, and the temperature difference between the outer and inner surface also increased;

3. The tilt angle of the cylinder had a small negative influence on the heat exchange. The influence of gravity worsened the liquid film uniformity;

4. A decrease of thermal conductivity of the cylinder body prolonged the stabilizing time of the system considerably. The system heat flux decreased significantly with the outer surface temperature, and the influence of the cylinder rotation speed became weaker.

\section{REFERENCES}

1. Pais, M.R., Chow, L.C., Mathefdey, E.T. Surface Roughness and its Effects on the Heat Transfer Mechanism in Spray Cooling ASME Journal of Heat Transfer 114 (1) 1992: pp. $211-219$. https://doi.org/10.1115/1.2911248

2. Isachenko, V.P., Kushnyrev, V.I., Gorin, S.V. Experimental Study of Heat Transfer in Cooling of a Vertical Surface by a Liquid Spray Heat Transfer-Soviet Research 11 1979: pp. $142-145$.

3. Karwa, N., Kale, S.R., Subbarao, P.M.V. Experimental Study of Non-Boiling Heat Transfer from a Horizontal Surface by Water Sprays Experimental Thermal and Fluid Science 32 (2) 2007: pp. 571-579.

4. Silk, E.A. Investigation of Enhanced Surface Spray Cooling. Investigation of Enhanced Surface Spray Cooling. Park: University of Maryland, 2006.
5. Silk, E.A., Kim, J., Kiger, K. Impact of Cubic Pin Finned Surface Structure Geometry Upon Spray Cooling Heat Transfer. San Francisco, California, 2005: pp. 1-9. https://doi.org/10.1115/IPACK2005-73003

6. Silk, E.A., Kim, J., Kiger, K. Spray Cooling Trajectory Angle Impact upon Heat Flux Using a Straight Finned Enhanced Surface. San Francisco, California, 2005: pp. $743-751$. https://doi.org/10.1115/HT2005-72634

7. Panão, M.R.O., Correia, A.M. High-Power Electronics Thermal Management with Intermittent Multi Jet Sprays Applied Thermal Engineering 37 2012: pp. 293-301.

8. Yoon, S.S., DesJardin, P.E., Presser, C., Hewson, J.C., Avedisian, C.T. Numerical Modeling and Experimental Measurements of Water Spray Impact and Transport Over a Cylinder International Journal of Multiphase Flow 32 (1) 2006: pp. $132-157$.

9. Reda, I.E. Experimental and Numerical Investigation of Heat Transfer from a Heated Horizontal Cylinder Rotating in Still Air Around its Axis Ain Shams Engineering Journal 5 (1) 2014: pp. $177-185$

10. Jafari, M. Analysis of Heat Transfer in Spray Cooling Systems Using Numerical Simulations. Ontario: University of Windsor, 2013.

11. Lu, S., Wang, Y.X., Sun, P., Lv, J.S. Experimental Investigation of Heat Transfer from Rotating Cylinder by Single-Nozzle Spraying Science Technology and Engineering 16 (12) 2016: pp. 252-256.

12. Mudawar, I., Estes, K.A. Optimizing and Predicting CHF in Spray Cooling of a Square Surface Journal of Heat Transfer 118 (3) 1996: pp. $672-679$. 